Article

\title{
A Unified Algorithm for the Atmospheric Correction of Satellite Remote Sensing Data over Land and Ocean
}

\author{
Zhihua Mao ${ }^{1,2, *}$, Delu Pan ${ }^{1}$, Xianqiang He ${ }^{1}$, Jianyu Chen ${ }^{1}$, Bangyi Tao ${ }^{1}$, Peng Chen ${ }^{1}$, \\ Zengzhou Hao ${ }^{1}$, Yan Bai ${ }^{1}$, Qiankun Zhu ${ }^{1}$ and Haiqing Huang ${ }^{1}$ \\ 1 State Key Laboratory of Satellite Ocean Environment Dynamics, Second Institute of Oceanography, \\ State Oceanic Administration, 36 Bochubeilu, Hangzhou 310012, China; pandelu@sio.org.cn (D.P.); \\ hexianqiang@sio.org.cn (X.H.); chenjianyu@sio.org.cn (J.C.); taobangyi@sio.org.cn (B.T.); \\ chenp@sio.org.cn (P.C.); hzyx80@sio.org.cn (Z.H.); baiyan@sio.org.cn (Y.B.); zhuqiankun@sio.org.cn (Q.Z.); \\ huanghaiqing@sio.org.cn (H.H.) \\ 2 Collaborative Innovation Center for South China Sea, Nanjing University, Nanjing 210046, China \\ * Correspondence: mao@sio.org.cn; Tel.: +86-571-8196-3121
}

Academic Editors: Xiaofeng Li and Prasad S. Thenkabail

Received: 29 February 2016; Accepted: 17 June 2016; Published: 24 June 2016

\begin{abstract}
The atmospheric correction of satellite observations is crucial for both land and ocean remote sensing. However, the optimal approach for each area is different due to the large spectra difference in the ground reflectance between land and ocean. A unified atmospheric correction (UAC) approach based on a look-up table (LUT) of in situ measurements is developed to remove this difference. The LUT is used to select one spectrum as the in situ ground reflectance needed to obtain the initial aerosol reflectance, which in turn is used for determining the two closest aerosol models. The aerosol reflectance, obtained from these aerosol models, is then used to deduce the estimated ground reflectance. This UAC model is then used to process the Sea-viewing Wide Field-of-view Sensor (SeaWiFS) data, and its performance is validated with a large number of in situ measurements. The mean bias of the land reflectance for this model is $6.59 \%$ with a root mean square error (RMSE) of $19.61 \%$. The mean bias and RMSE of the water-leaving reflectance are $7.59 \%$ and $17.10 \%$ validated by the in situ measurements using the above-water method, while they are $13.60 \%$ and $22.53 \%$ using the in-water method. The UAC model provides a useful tool for correcting the satellite-received reflectance without separately having to deal with land and ocean pixels. Further, it can seamlessly expand the satellite ocean color data for terrestrial use and improve quantitative remote sensing over land.
\end{abstract}

Keywords: atmospheric correction; land remote sensing; ocean color remote sensing; aerosol remote sensing; reflectance

\section{Introduction}

When studying the water quality of coastal regions, it is apparent that the majority of oceanic pollution is derived from land. The remote sensing of land provides a useful large-scale tool to demonstrate the relationship between river inputs and the water quality distribution. However, the large difference in ground reflectance between land and ocean has led the remote sensing community to develop separate approaches for atmospheric correction over land and ocean regions over the past few decades. Because satellites measure the reflectance at the top of the atmosphere (TOA) and do not separate land and ocean regions, a unified atmospheric correction algorithm would be useful for obtaining imagery of the ground reflectance. One significant benefit is that it would facilitate the study of phytoplankton growth rhythms relative to plant behavior in terrestrial phenology. 
Ever since Gordon [1] designed an atmospheric correction method based on a black ocean assumption (BOA) for two near-infrared (NIR) bands, this methodology has been widely applied in the processing of satellite ocean color data. The performance of Gordon's approach was improved significantly by adding the consideration of multiple scattering effects in computing the Rayleigh and aerosol scattering components, absorption in the oxygen A-band, the polarization effect, sea surface roughness and a bidirectional reflectance distribution function over the ocean [2-8]. However, this approach still faces problems for turbid waters due to the inapplicability of the BOA to these waters $[9,10]$. Several new approaches have been attempted to correct for these deficiencies for coastal waters [11-16]. Other approaches have been developed using spectral optimization algorithms [17-20] or the neural network methods [21,22] to obtain the oceanic and atmospheric parameters simultaneously from the satellite-received reflectance at the TOA.

The atmospheric correction over land is faced with more complex situations. Analogous to the BOA approach for ocean color remote sensing, the dark target (DT) approach has been widely used in atmospheric correction schemes to estimate the optical properties of aerosols over land [23,24]. As the magnitude of the reflectance varies significantly over different types of the land cover and the degree of vegetative coverage, the DT approach is limited to use in regions with either dense vegetation or water. Other approaches have been developed using different methods, such as the invariant object approach of Hall et al. [25], the histogram matching of Richter [26], the contrast reduction of Tanre and Legrand [27] and the radiative transfer model from Gao et al. [28]. However, the effect of the atmospheric correction on the different vegetation indices has been shown to be significant [29-31].

Land regions have significant surface reflectance in the NIR bands, while ocean reflectance in this band is quite low. Therefore, different approaches to the atmospheric correction are necessary for land and ocean to optimize the correction in each case. However, a unified algorithm provides an approach to obtain the ground reflectance with the same methodology for both land and ocean. Recently, Mao et al. [32,33] developed an approach to estimate the aerosol scattering reflectance over turbid waters based on a look-up table (LUT) of in situ measurements. Following this approach, a unified atmospheric correction (UAC) approach is developed in this paper for both land and ocean.

Ocean color satellites, which were designed to meet the requirements of ocean remote sensing, also have some intrinsic advantages in land remote sensing. The high signal-to-noise ratio of the satellite sensor, typically several times higher than that for satellites designed for land use, is beneficial for the study of terrestrial ecosystems. The high accuracy of the satellite-received reflectance, well calibrated by on-board systems, obviously benefits the quantitative remote sensing over land. However, presently, their terrestrial use is limited by the problem of the atmospheric correction over land. The UAC model provides a potential approach for extending the ocean color satellite data into terrestrial applications.

\section{The UAC Model}

The satellite-received reflectance at the TOA is defined by:

$$
\rho_{\mathrm{t}}(\lambda)=\frac{\pi \mathrm{L}_{\mathrm{t}}(\lambda)}{\mathrm{F}_{0}(\lambda) \cos \theta_{0}}
$$

where $L_{t}(\lambda)$ is the satellite-measured radiance, $F_{0}(\lambda)$ is the extraterrestrial solar irradiance and $\theta_{0}$ is the solar-zenith angle. Wang [8] partitioned the term $\rho_{t}(\lambda)$ into several components each corresponding to a distinct physical process:

$$
\begin{gathered}
\rho_{\mathrm{t}}(\lambda)=\rho_{\mathrm{r}}(\lambda)+\rho_{\mathrm{A}}(\lambda)+\mathrm{t}(\lambda) \rho_{\mathrm{wc}}(\lambda)+\mathrm{T}(\lambda) \rho_{\mathrm{g}}(\lambda)+\mathrm{t}(\lambda) \rho_{\mathrm{w}}(\lambda), \text { for ocean waters and } \\
\rho_{\mathrm{t}}(\lambda)=\rho_{\mathrm{r}}(\lambda)+\rho_{\mathrm{A}}(\lambda)+\mathrm{t}(\lambda) \rho_{\mathrm{s}}(\lambda), \text { for land regions }
\end{gathered}
$$

where $\rho_{\mathrm{r}}(\lambda)$ is the Rayleigh scattering reflectance due to the air molecules, $\rho_{\mathrm{A}}(\lambda)$ is the aerosol scattering reflectance including the Rayleigh-aerosol interactions, $\rho_{\mathrm{wc}}(\lambda)$ is the reflectance of the ocean whitecaps, $\rho_{\mathrm{g}}(\lambda)$ is the reflectance of Sun glitter off the sea surface and $\rho_{\mathrm{w}}(\lambda)$ is the water-leaving 
reflectance. The terms $t(\lambda)$ and $\mathrm{T}(\lambda)$ are the diffuse and direct transmittances of the atmosphere, respectively. The term $\rho_{\mathrm{s}}(\lambda)$ is the ground reflectance over land, and the interaction effect between the land reflection and the atmosphere is neglected.

The above equation can be rewritten as:

$$
\rho_{\text {aw }}(\lambda)=\rho_{\mathrm{A}}(\lambda)+\mathrm{t}_{\mathrm{a}}(\lambda) \rho_{\mathrm{s}}(\lambda)
$$

where $\rho_{\mathrm{aw}}(\lambda)=\rho_{\mathrm{t}}(\lambda)-\rho_{\mathrm{r}}(\lambda)$ over land and $\rho_{\mathrm{aw}}(\lambda)=\rho_{\mathrm{t}}(\lambda)-\rho_{\mathrm{r}}(\lambda)-\mathrm{t}(\lambda) \rho_{\mathrm{wc}}(\lambda)-\mathrm{T}(\lambda) \rho_{\mathrm{g}}(\lambda)$ overthe ocean. The term $t_{a}(\lambda)$ is the net transmittance of the aerosol after the removal of the Rayleigh scattering and atmospheric absorption. The term $\rho_{\mathrm{S}}(\lambda)$ is the water-leaving reflectance over the ocean. The term $\rho_{\text {aw }}(\lambda)$ is the ground-aerosol reflectance and is composed of both the aerosol and ground reflectance.

The aerosol transmittance is computed from the expression given by Gordon and Castasno [2]:

$$
\mathrm{t}_{\mathrm{a}}(\lambda)=\exp \left(-\frac{\left[1-\omega_{\mathrm{a}}(\lambda) \mathrm{F}(\lambda)\right] \tau_{\mathrm{a}}(\lambda)}{\cos \theta_{\mathrm{v}}}\right)
$$

where $\omega_{\mathrm{a}}(\lambda)$ is the single-scattering albedo, $\mathrm{F}(\lambda)$ is the probability that a photon is scattered by the aerosol through an angle of $<90^{\circ}, \tau_{\mathrm{a}}(\lambda)$ is the aerosol optical thickness (AOT) and $\theta_{0}$ is the sensor-zenith angle of the satellite. The factor $\left[1-\omega_{a}(\lambda) F(\lambda)\right]$ is relatively small with an upper limit of 0.1667 according to Gordon and Castasno [2]. Therefore, Equation (4) can be approximated by:

$$
\mathrm{t}_{\mathrm{a}}(\lambda) \leqslant 1-0.1667 \tau_{\mathrm{a}}(\lambda) / \cos \theta_{\mathrm{v}}
$$

The error of this approximation increases with increasing values of the AOT. For example, when the $\mathrm{AOT}=0.1$, the relative error is $0.53 \%$. In practice, the error introduced by this approximation was acceptable. The term $\tau_{a}(\lambda)$ was given by Gordon [3-5]:

$$
\tau_{\mathrm{a}}(\lambda)=4 \rho_{\mathrm{a}}(\lambda) \cos \theta_{\mathrm{v}} \cos \theta_{0} /\left(\omega_{\mathrm{a}}(\lambda) \mathrm{P}_{\mathrm{a}}\left(\theta_{\mathrm{v}}, \vartheta_{\mathrm{v}} ; \theta_{0}, \vartheta_{0}, \lambda\right)\right)
$$

where $\rho_{\mathrm{a}}(\lambda)$ is the aerosol scattering reflectance, $\mathrm{P}_{\mathrm{a}}$ is the aerosol scattering phase function and $\vartheta_{\mathrm{v}}$ and $\vartheta_{0}$ are the azimuth angles of the satellite and the Sun, respectively.

When $\rho_{\mathrm{A}}(\lambda)$ in Equation (3) is transformed to $\rho_{\mathrm{a}}(\lambda)$ according to Wang [13], $\rho_{\mathrm{aw}}(\lambda)$ turns out to be related to the components of $\rho_{\mathrm{a}}(\lambda)$ and $\rho_{\mathrm{s}}(\lambda)$. With $\rho_{\mathrm{s}}(\lambda)$ obtained from the LUT of in situ measurements using the method developed by Mao et al. [32,33], $\rho_{\mathrm{a}}(\lambda)$ can be computed from Equation (3) and used to determine the two closest aerosol models. The estimated aerosol scattering reflectance, $\rho_{\mathrm{a}}^{\mathrm{n}}(\lambda)$, is deduced from the two aerosol models and used to obtain the aerosol reflectance, including the Rayleigh-aerosol interactions, $\rho_{A}^{\mathrm{n}}(\lambda)$, according to Wang [13]. The estimated surface reflectance, $\rho_{\mathrm{s}}^{\mathrm{n}}(\lambda)$, is then obtained by:

$$
\rho_{\mathrm{s}}^{\mathrm{n}}(\lambda)=\left(\rho_{\mathrm{aw}}(\lambda)-\rho_{\mathrm{A}}^{\mathrm{n}}(\lambda)\right) / \mathrm{t}_{\mathrm{a}}(\lambda)
$$

The critical procedure in the atmospheric correction is how the aerosol reflectance is separated from the ground reflectance. Normally, the aerosol reflectance is first estimated in the atmospheric correction, but this estimation meets an obstacle when both terms are unknown over turbid waters or land. However, if the ground reflectance has been measured, the aerosol reflectance can be easily obtained from Equation (3). While it is impossible to make in situ measurements for each pixel of the satellite imagery, enough in situ measurements have been collected so that it is possible to determine the most typical reflectance of different objects on the land and in the ocean. The critical procedure turns out to be how to select the best spectral reflectance from the LUT as the initial ground reflectance. The main framework of the UAC model is shown in Figure 1. 


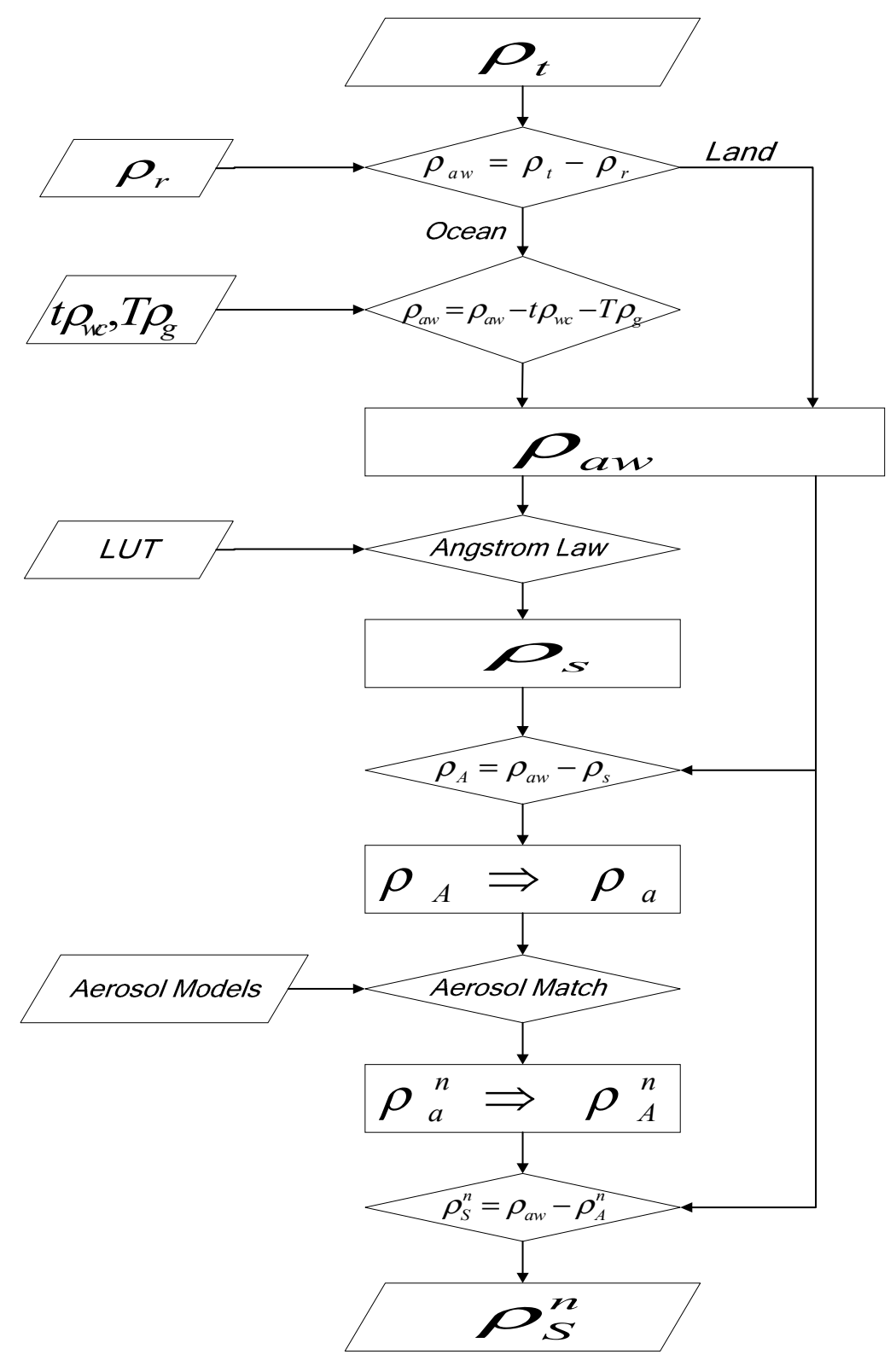

Figure 1. The flow chart of the UAC model.

The Rayleigh scattering reflectance, $\rho_{\mathrm{r}}(\lambda)$, needs to be accurately computed to obtain the ground-aerosol reflectance, $\rho_{\mathrm{aw}}(\lambda)$, for both land and ocean. For the ocean, the reflectance of the ocean whitecaps and Sun glitter off the sea surface are also computed along with their transmittance. The LUT is used to obtain the in situ ground reflectance, $\rho_{\mathrm{s}}(\lambda)$, based on Angström's law. The component, $\rho_{\mathrm{S}}(\lambda)$, is used to compute the aerosol scattering reflectance, including the Rayleigh- aerosol interactions, $\rho_{\mathrm{A}}(\lambda)$, which is transformed to obtain the aerosol scattering reflectance, $\rho_{\mathrm{a}}(\lambda)$. The aerosol models are used to match the two closest models, which are then used to compute the estimated aerosol reflectance, $\rho_{\mathrm{a}}^{\mathrm{n}}(\lambda)$. The aerosol reflectance, including the Rayleigh-aerosol interactions, $\rho_{\mathrm{A}}^{\mathrm{n}}(\lambda)$, is transformed from $\rho_{\mathrm{a}}^{\mathrm{n}}(\lambda)$ and then used to obtain the ground reflectance, $\rho_{\mathrm{s}}^{\mathrm{n}}(\lambda)$.

Normally, the atmospheric correction methods, like the BOA and DT, are plagued by the varying ground reflectance of different objects. However, in the UAC approach, the difference in the ground reflectance is represented by distinct spectra in the LUT, and all spectra in the LUT play the same role. Therefore, the LUT of the in situ reflectance helps the UAC model eliminate the differential effects of the atmospheric correction between land and ocean. The LUT has no flag indicating land or ocean, nor 
does it have information indicating location and time. Consequently, it has the potential to be used at the global scale.

\section{Testing the UAC Model Using SeaWiFS Data}

SeaWiFS data covering the Chinese coastal region have been collected since 1997, and all data have been reprocessed with the UAC model to enable the evaluation of its performance. One sample of nearly cloud-free satellite imagery was selected for initial comparison and is shown in Figure 2a. It is a composite image of the satellite-received reflectance at the TOA on 24 December 2003. The image covers the Yangtze River Delta region and the East China Sea, a region in China with significant industrial and urban development. It covers an area with a complex structure of ground reflectance ranging from very turbid waters to nearly clear oceanic waters. The image shows a mixture of reflectance signals, including Rayleigh scattering and reflections from clouds, aerosols and the ocean and land surfaces. The challenge is to accurately separate each of these components from the satellite-received reflectance.
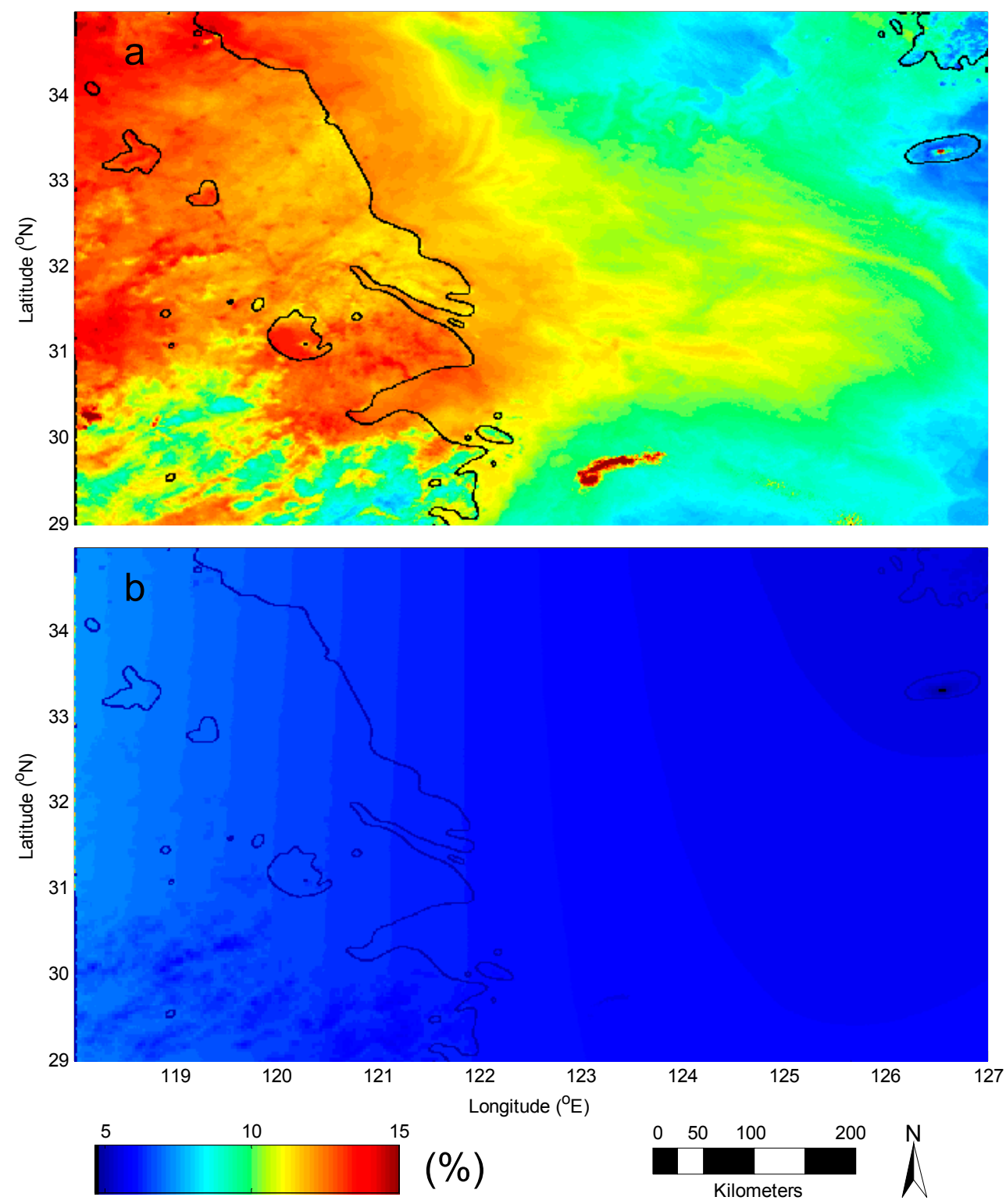

Figure 2. (a) The image of the satellite-received reflectance at the TOA from SeaWiFS data on 24 December 2003 and (b) the Rayleigh reflectance computed by the UAC model. Both images are the reflectance at Band $3(490 \mathrm{~nm})$ with values indicated by the color bar. The unit is percentage. 
The Rayleigh reflectance is normally computed in different ways between land and ocean. It is computed without the interaction between the atmosphere and ground surface for the land, while it includes the interaction between Rayleigh and sea-surface reflection for ocean. The UAC model uses the same Rayleigh computational method for the ocean and land. The interaction between Rayleigh and the sea-surface is removed, and it is included in the component of the Sun glitter. The Rayleigh reflectance over land is corrected for the elevation of the land surface. Figure $2 \mathrm{~b}$ shows the Rayleigh reflectance computed under the same satellite observing conditions as in Figure 2a. Except for some variation due to attitude corrections in the mountainous region at the southwestern corner of the image [34], the spatial variation of the Rayleigh reflectance is relatively small. In fact, the difference in the Rayleigh reflectance between land and ocean is essentially negligible. Comparing the two images in Figure 2, the color of the Rayleigh is similar to that of the satellite reflectance over some oceanic waters, indicating that the Rayleigh takes the most part of the reflectance at the TOA under the clear sky over the oceanic waters.

The UAC model is used to obtain the aerosol and ground reflectance patterns shown in Figure 3a,b, respectively. The spatial structure of the aerosol image is significantly different from that of the ground reflectance. Figure 3a shows large spatial variations of the aerosol reflectance with the highest values occurring over the region around Shanghai and Lake Taihu. The image shows a coherent spatial structure with many features extending from the land out over the coastal ocean. It is noteworthy that there is almost no difference in the aerosol reflectance between ocean and nearby land areas. This spatial distribution of aerosols demonstrates that one strength of the UAC model is that it can estimate the aerosol reflectance without discontinuity between land and ocean. The image in Figure 3b shows the landscapes around Shanghai, Jiangsu and Zhejiang together with the Changjiang River and Lake Taihu. The magnitudes of the water-leaving reflectance from the Subei coast, Changjiang Estuary and Hangzhou Bay are very high, while the reflectance is relatively low over the outer shelf regions of the East China Sea. Taken together, the images in Figure 3 demonstrate that the UAC model is capable of cleanly separating the ground reflectance from the aerosol reflectance over land and ocean.

The land reflectance increases with increasing wavelengths, the mean spectrum going from $4.09 \%$ at $412 \mathrm{~nm}$ to $18.23 \%$ at $865 \mathrm{~nm}$ (Figure $4 \mathrm{a}$ ). The spatial variations of the reflectance in Band 1 $(1.87 \%-5.85 \%)$ are relatively small, while those in Band $8(9.16 \%-24.05 \%)$ are quite large. The shapes of the three land spectra are similar, demonstrating that the averaging effect on the $1-\mathrm{km}^{2}$ scale of a pixel significantly reduces the variability in the spectra of the ground reflectance. However, the wavelength dependence in the ocean reflectance is quite different, indicating that there is significant spatial variability in the reflectance between different water types (Figure 4b). In particular, the wavelength of the maximum reflectance shifts toward shorter wavelengths, and the magnitudes become smaller as the location changes from very turbid waters to clear oceanic waters. The variation of the reflectance in Band 6 is the largest, with a range of $0.31 \%-11.37 \%$. The $\mathrm{P}_{05}$ spectra are more typical of the reflectance of clear oceanic waters with negligible values in Band 8, while the $\mathrm{P}_{95}$ spectra represent spectra from turbid waters with quite large values in the near-infrared band. Although the aerosol reflectance decreases with increasing wavelength, their shapes differ in the shorter bands due to the effects of multiple scattering (Figure $4 c, d$ ). In addition, the aerosol values are close to or higher than those of the land reflectance at visible bands (Figure $4 \mathrm{a}, \mathrm{c}$ ), indicating that the atmospheric correction of the satellite reflectance over land is necessary. 

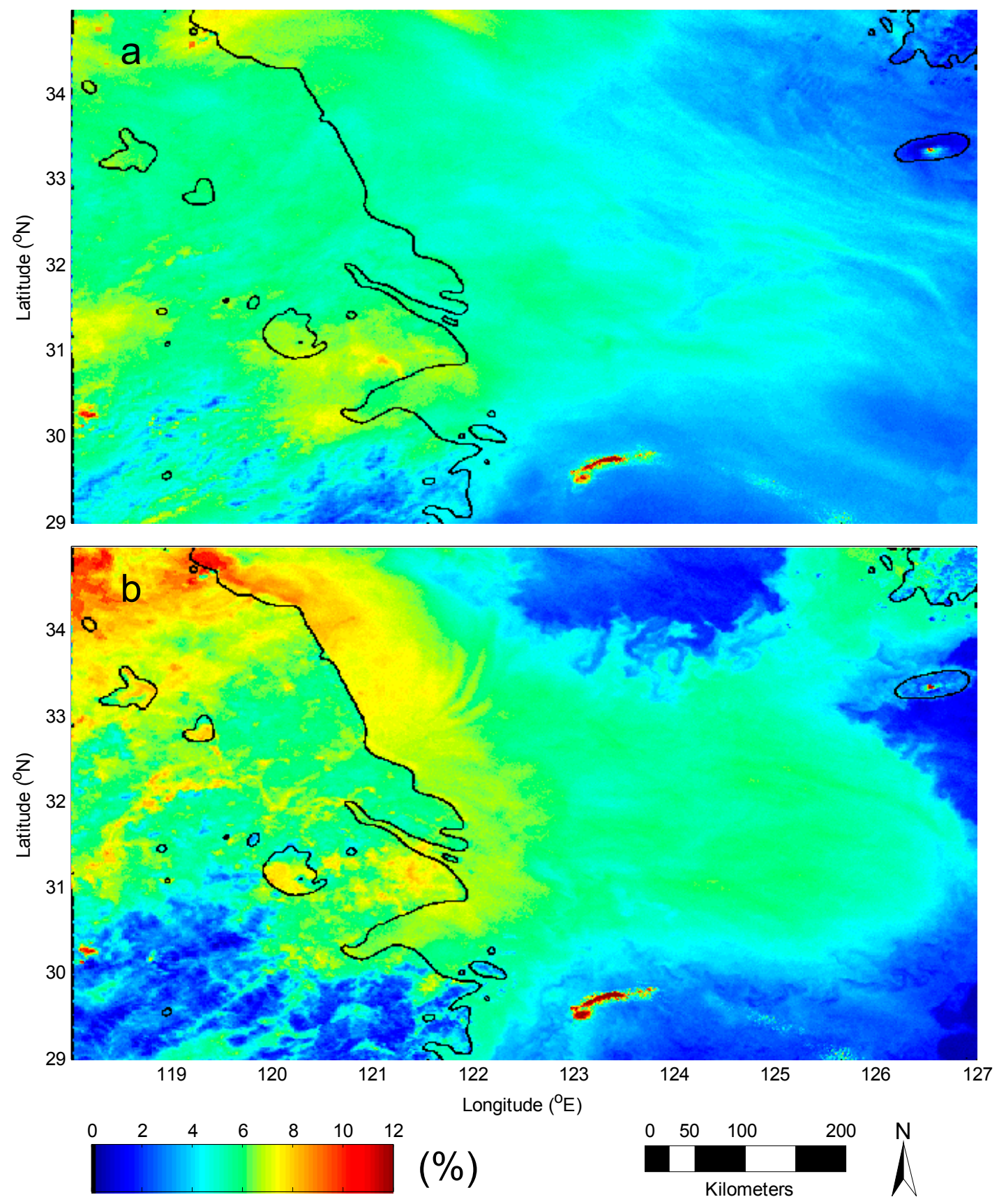

Figure 3. (a) The aerosol reflectance and (b) the ground reflectance obtained by the UAC model from SeaWiFS data on 24 December 2003. Both images are the reflectance at Band $3(490 \mathrm{~nm})$ with values indicated by the color bar. Another distinct advantage of the UAC model is that it can derive the ground reflectance of all eight SeaWiFS wavelength bands for both land and ocean. The reflectance in the near-infrared band is important for obtaining the total suspended matter in turbid waters and the normalized difference vegetation index (NDVI) over land. The resulting reflectance spectra of the ground and aerosols over land and ocean are shown in Figure 4. It is clear from this figure that the wavelength dependence of the aerosol reflectance over land is very similar to that over the ocean. 

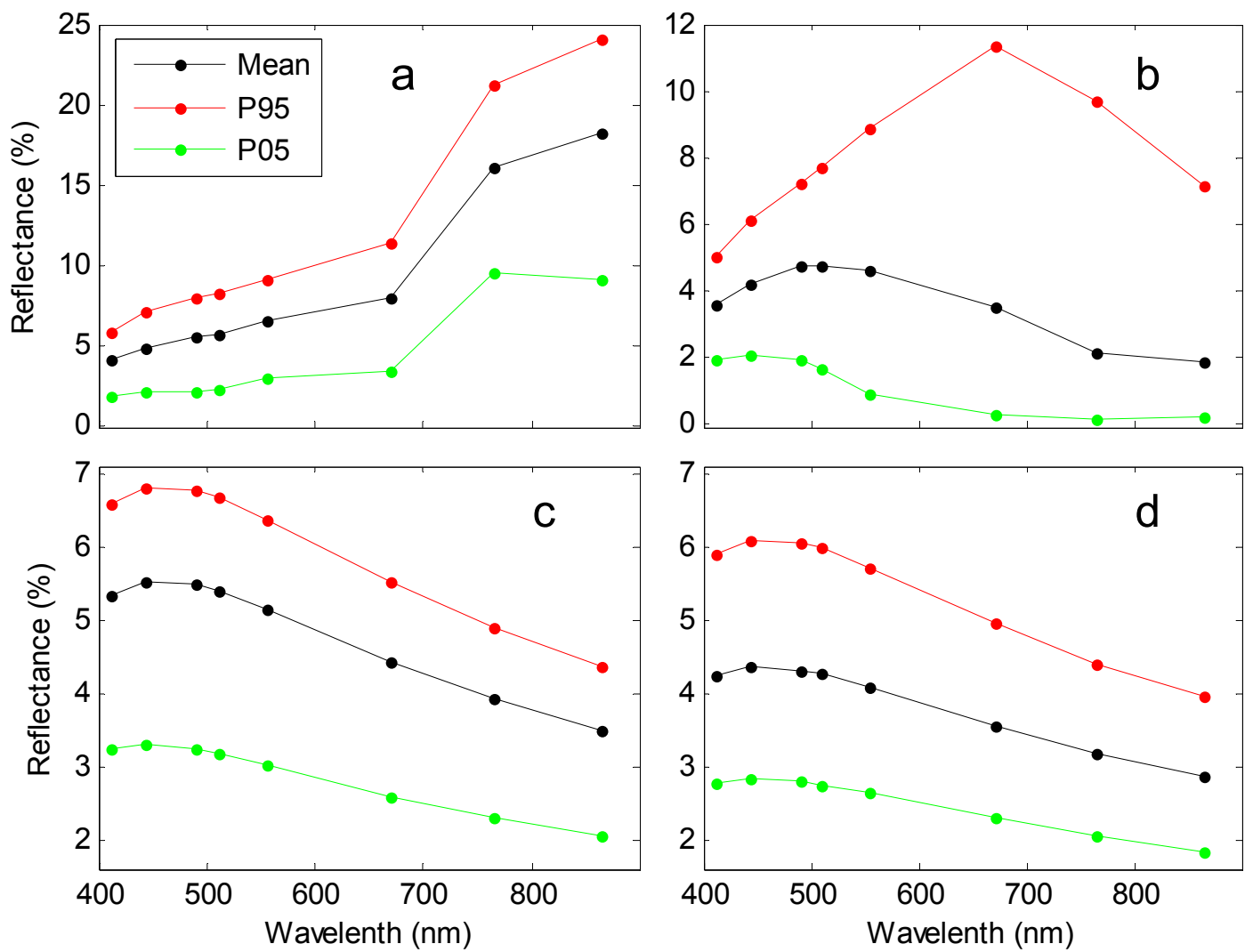

Figure 4. The ground and aerosol reflectance spectra obtained from the SeaWiFS data in Figure 3. The three curves represent the mean, P05 and P95 percentages of the (a) ground reflectance over land; (b) ground reflectance over the ocean; (c) aerosol reflectance over land and (d) aerosol reflectance over the ocean. The P05 (5\%) and P95 (95\%) percentages are used to remove the outliers for the minimum and maximum of the reflectance.

\section{Comparing Results of the UAC Model to in Situ Measurements}

To evaluate the performance of the UAC model in processing SeaWiFS data, a comparison between the satellite-derived reflectance and in situ measurements was made. While we focus on satellite ocean color remote sensing, the number of in situ measurements on land was limited, and many of them were located in the coastal regions. However, we did obtain many in situ reflectance observations over land from some organizations. The locations of the land sites used in the paper are shown with red dots in Figure 5, together with the stations for the water-leaving reflectance using both the above-water and in-water methods. In total, there are data on the in situ reflectance from 740 land sites, 414 above-water stations and 272 in-water stations.

Ideally, the validation of the satellite-derived reflectance would be based on the simultaneous measurement of an object by both the satellite and in situ station. However, this requirement is difficult to achieve in establishing the matched pairs. Each pixel from the SeaWiFS imager represents an average of the reflectance over a $1-\mathrm{km}^{2}$ area, while the in situ measurements are typically limited to an area of $\sim 1-\mathrm{m}^{2}$. Therefore, at least one million in situ reflectance measurements would need to be made and averaged to the SeaWiFS image to cover the area of one pixel. Further, to be an exact match, the borders of the SeaWiFS pixel on the ground would need to be known to obtain the precise reflectance of the pixel. The other issue is to determine how wide of a time window between the satellite pass and in situ measurement is acceptable for the matched pairs. Obviously, the time can be somewhat longer for the land reflectance because it is relatively stable, while it would need to be shorter for evolving ocean regions. This is especially true for the rapidly varying coastal waters that evolve on tidal time scales or shorter. Considering the complexity in establishing the matched pairs, a closest matching method 
based on the smallest reflectance difference between the satellite-derived and in situ measurements with a variable window time is developed for the evaluation of the performance of the UAC model.

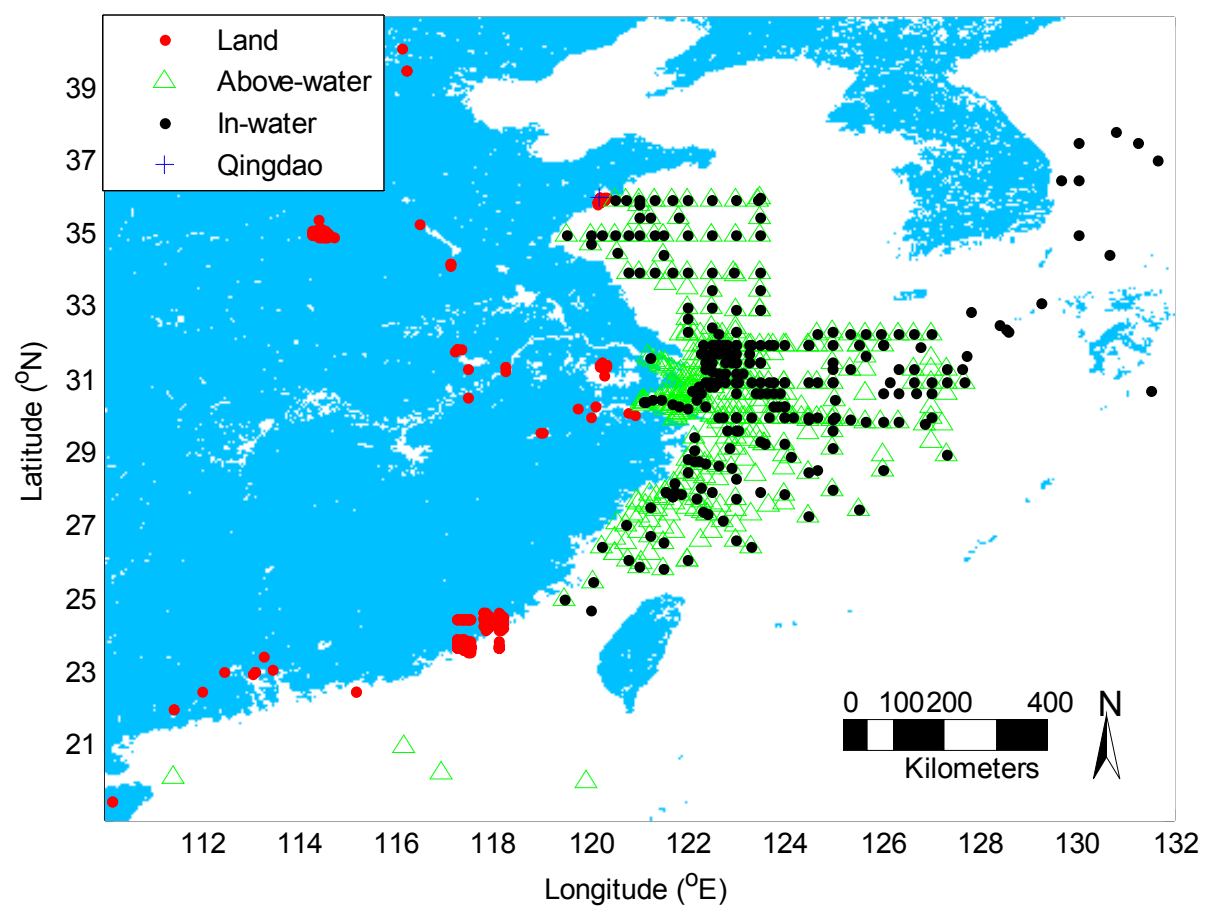

Figure 5. Locations of in situ measurements used to estimate the accuracy of the UAC model. Land sites are marked by red dots; ocean stations using the above-water method are marked by green triangles; and ocean stations using the in-water method by black dots.

The mean bias and root mean square error (RMSE) are used to compute the accuracy.

$$
\begin{gathered}
x=100 \times\left(\rho_{\text {sat }}-\rho_{m}\right) / \rho_{m} \\
\text { Bias }=\frac{1}{\mathrm{n}} \sum_{\mathrm{i}=1}^{\mathrm{n}} \mathrm{x}_{\mathrm{i}} \\
\operatorname{RMSE}=\left[\frac{1}{\mathrm{n}-1} \sum_{\mathrm{i}=1}^{\mathrm{n}}\left(\mathrm{x}_{\mathrm{i}}-\overline{\mathrm{x}}\right)^{2}\right]^{\frac{1}{2}}
\end{gathered}
$$

where $\rho_{\text {sat }}$ and $\rho_{m}$ are the reflectance of the satellite-estimated and in situ measured, respectively. The bias and RMSE are used to evaluate the accuracy of the satellite-estimated reflectance with the systematic error and random error, respectively. The RMSE is actually the standard deviation of the relative error.

\subsection{Comparing the Land Reflectance to in Situ Measurements}

The in situ reflectance from land is obtained from measurements using a hyperspectral spectrometer manufactured by Analytical Spectral Devices Incorporation (ASD). The ASD measures the reflectance in 512 wavelength bands over the range of 325-1070 nm with a spectral width of about $2.54 \mathrm{~nm}$, and the SeaWiFS sensor has eight bands over 402-885 nm with spectral widths of $20-40 \mathrm{~nm}$. Consequently, the reflectance from the ASD is computed into the eight bands using the spectral response of SeaWiFS eight-band sensors. We have collected a total of 1323 reflectance measurements of different land objects from 740 sites, which include the reflectance of beaches, roads, rocks, soils, rice fields, trees and grasslands. 
Some difficulty occurred in establishing the matched pairs for correcting the reflectance over land. For example, some in situ reflectance measurements taken at beaches showed large variations from dry to wet sands across the beach profile. Further, beach widths are typically shorter than $1 \mathrm{~km}$ and extend from the water's edge to a complicated mixture of objects at their shoreward limit. In addition, the beach width changes with the progression of the tide, so that the actual effective value of the satellite-measured reflectance will be determined by the mean of the reflectance of the area within the image pixel over the time the satellite image was obtained. However, the biggest difficulty is in how to determine an appropriate mean value for reflectance from in situ measurements. Because the in situ objects measured are randomly distributed over the pixel and the reflectance varies significantly between different objects within the area of one pixel, the mean of measured reflectance within the pixel area may not adequately represent the true values to evaluate the accuracy of the satellite reflectance. Further, when a one-hour time window rule is adopted for in situ and satellite observations of the same location under cloud-free conditions to define matched pairs, only nine pairs were identified. The closest matching method with a time window of 15 days was used to establish the matching pairs; a total of 864 pairs were obtained for the validation (Figure 6).
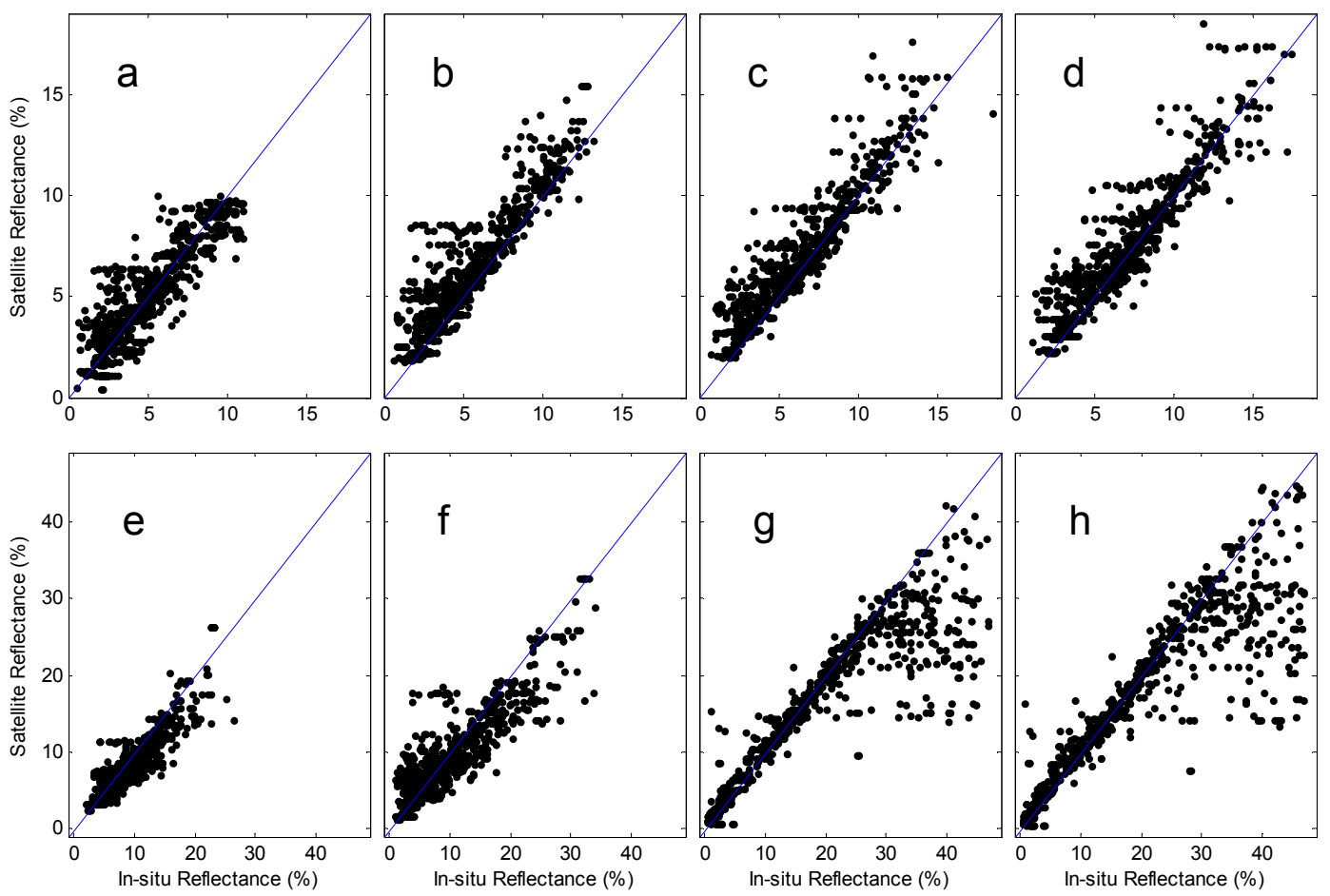

Figure 6. The comparisons of the land reflectance between the satellite-derived and in situ measurements for SeaWiFS Bands 1-8 are shown in (a-h), respectively.

The comparisons between the satellite observations and in situ measurements for the eight SeaWiFS bands are shown in Figure 6, with most matched points clustering around the 1:1 line. The mean bias and RMSE of the satellite-derived reflectance for each band is listed in Table 1. These biases vary from $-14.84 \%$ in Band $2(443 \mathrm{~nm})$ to $+7.41 \%$ in Band $5(555 \mathrm{~nm})$ with a mean bias of $6.59 \%$. The small mean bias indicates that overall, the satellite-derived reflectance is in good agreement with the in situ measurements. Since both reflectance measurements are normalized by the incoming solar irradiance, the influence of different measurement time is significantly reduced. Moreover, the fact that the land reflectance remains relatively stable over a long period significantly reduces the impact of the 15-day time window for defining the matched pairs. The RMS error values vary from $13.74 \%$ in Band 5 (555 nm) to $22.27 \%$ in Band $8(865 \mathrm{~nm})$ with a mean of $19.61 \%$. 
Table 1. The mean bias and RMSE of the satellite-derived reflectance over land.

\begin{tabular}{cccccccccc}
\hline Wavelength (nm) & $\mathbf{4 1 2}$ & $\mathbf{4 4 3}$ & $\mathbf{4 9 0}$ & $\mathbf{5 1 0}$ & $\mathbf{5 5 5}$ & $\mathbf{6 7 0}$ & $\mathbf{7 6 5}$ & $\mathbf{8 6 5}$ & Mean \\
\hline Bias (\%) & -0.68 & -14.84 & -13.40 & -8.91 & 7.41 & 2.12 & -1.92 & -3.47 & 6.59 \\
RMSE (\%) & 21.19 & 20.74 & 19.07 & 17.40 & 13.74 & 20.54 & 21.96 & 22.27 & 19.61 \\
\hline
\end{tabular}

While the bias and RMSE results are quite good, there are some pairs that show significant differences between the satellite and in situ reflectance. Specifically, the maximum satellite reflectance is less than $45 \%$, while there are some in situ reflectance values higher than $50 \%$. For example, the in situ snow reflectance is very high, with some values exceeding $90 \%$, while the satellite-derived reflectance is reduced significantly by the effect of partial snow cover. Therefore, matched pairs with values higher than $45 \%$ are taken as the outliers and removed from the validation.

\subsection{Comparing the Water-Leaving Reflectance to in Situ Measurements Using the Above-Water Method}

The water-leaving reflectance was measured by the ASD spectrometer using the above-water method at the stations shown in Figure 5. Because some stations were repeated during subsequent cruises, the number of ASD reflectance measurements is larger than the number of stations. The closest matching method is also used with a three-day time window under cloud-free conditions. A total of 1364 pairs are obtained for the comparison of the reflectance in the eight SeaWiFS bands (Figure 7). As in the previous case, most points are tightly clustered around the 1:1 line.
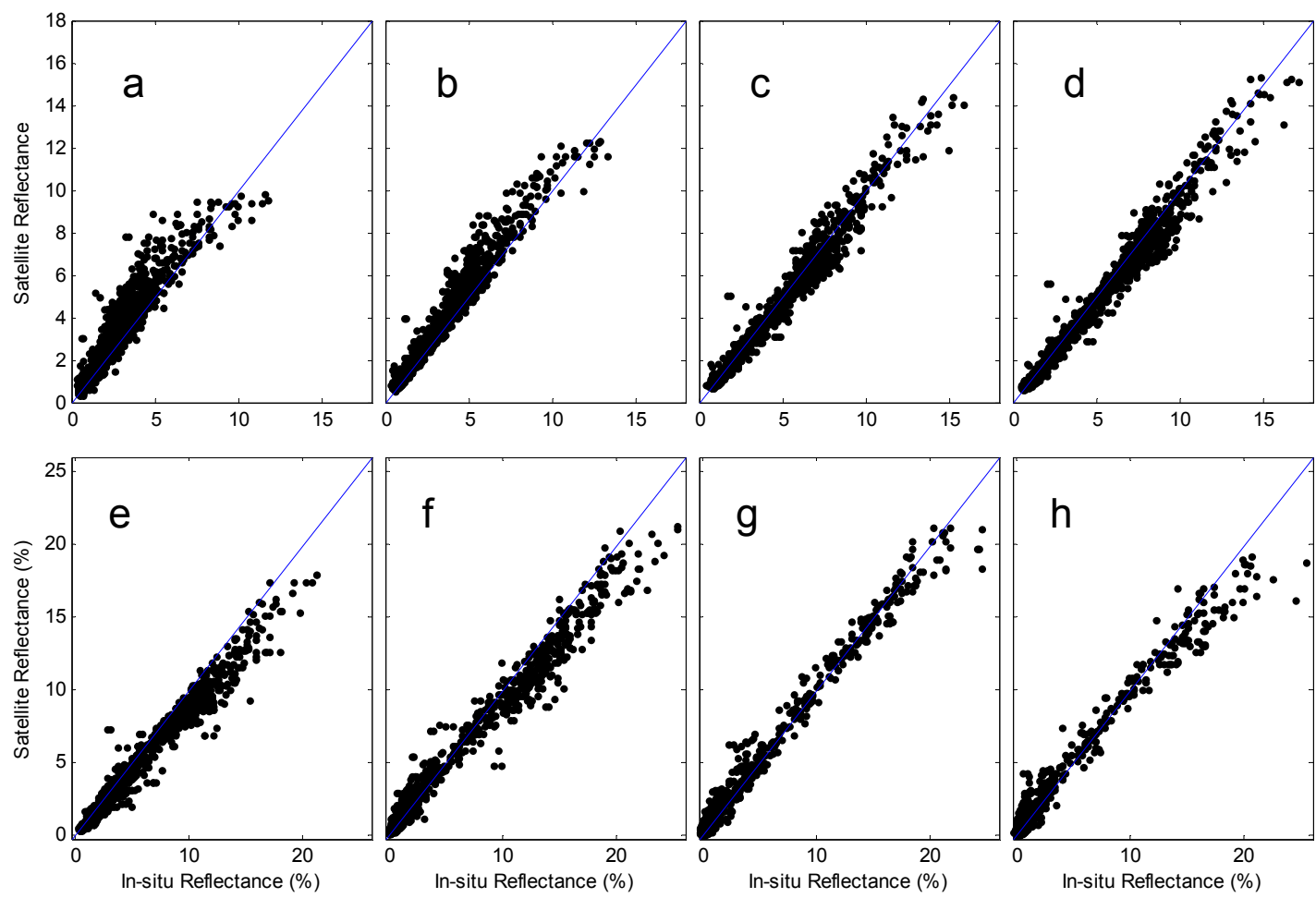

Figure 7. The comparisons of the satellite-derived water-leaving reflectance to in situ measurements using the above-water method with Bands 1-8 are shown in (a-h), respectively.

It is obvious that different criteria for building matched pairs can lead to different results in the evaluation. The closest matching method can reduce the difference between satellite and in situ measurements arising from variations in the ocean dynamics. For example, the magnitude of the reflectance can vary by more than $100 \%$ over the period of one hour in Hangzhou Bay and other regions. Further, the accuracy of the ASD reflectance itself can be dramatically affected by sunlight 
reflected off the sea surface, which in turn can vary significantly due to differences in wind speed, Sun-viewing angles and other factors. Frequently, the difference in the in situ reflectance between two measurements of the same station separated by about 30 min can exceed $10 \%$.

The mean bias and RMSE of the satellite reflectance in the eight SeaWiFS bands are listed in Table 2. The bias values vary from $-18.21 \%$ in Band 1 to $10.49 \%$ in Band 5 with a mean of $7.59 \%$. Likewise, the RMSE values vary from $8.11 \%$ to $26.54 \%$ with a mean of $17.10 \%$. One advantage of the ASD above-water method measurement is to validate the reflectance of SeaWiFS imagery over all eight bands instead of the five bands used by Bailey and Werdell [35].

Table 2. The performance of the UAC model using in situ reflectance by the above-water method.

\begin{tabular}{cccccccccc}
\hline Wavelength (nm) & $\mathbf{4 1 2}$ & $\mathbf{4 4 3}$ & $\mathbf{4 9 0}$ & $\mathbf{5 1 0}$ & $\mathbf{5 5 5}$ & $\mathbf{6 7 0}$ & $\mathbf{7 6 5}$ & $\mathbf{8 6 5}$ & Mean \\
\hline Bias (\%) & -18.21 & -12.50 & 2.13 & 3.55 & 10.49 & -6.06 & -6.36 & 1.39 & 7.59 \\
RMSE (\%) & 20.83 & 14.51 & 8.84 & 8.11 & 10.62 & 20.97 & 26.39 & 26.54 & 17.10 \\
\hline
\end{tabular}

\subsection{Comparing the Water-Leaving Reflectance to in Situ Measurements Using the In-Water Method}

The Satlantic profiling spectrometer and reference system is used to measure the water-leaving reflectance by the in-water method for the station locations shown in Figure 5. The number of stations in the Yangtze Estuary and Hangzhou Bay is much smaller than that for the above-water method because the in-water method cannot be used in the coastal areas with high turbidity and/or shallow water. The data quality is cross-examined by comparison with the reflectance measurements using the above method at the same stations where possible. The closest matching method with a three-day time window was also used to obtain the matched pairs. A total of 923 pairs were obtained for the comparison of the reflectance results shown in Figure 8. There are a total of 2187 pairs for the ocean validation from the above-water and in-water methods, much larger than the number of the pairs in the validation of SeaWiFS in the global ocean by Bailey and Werdell [35] (a maximum of 629 with a range of 406-629 pairs for the different wavelength bands).
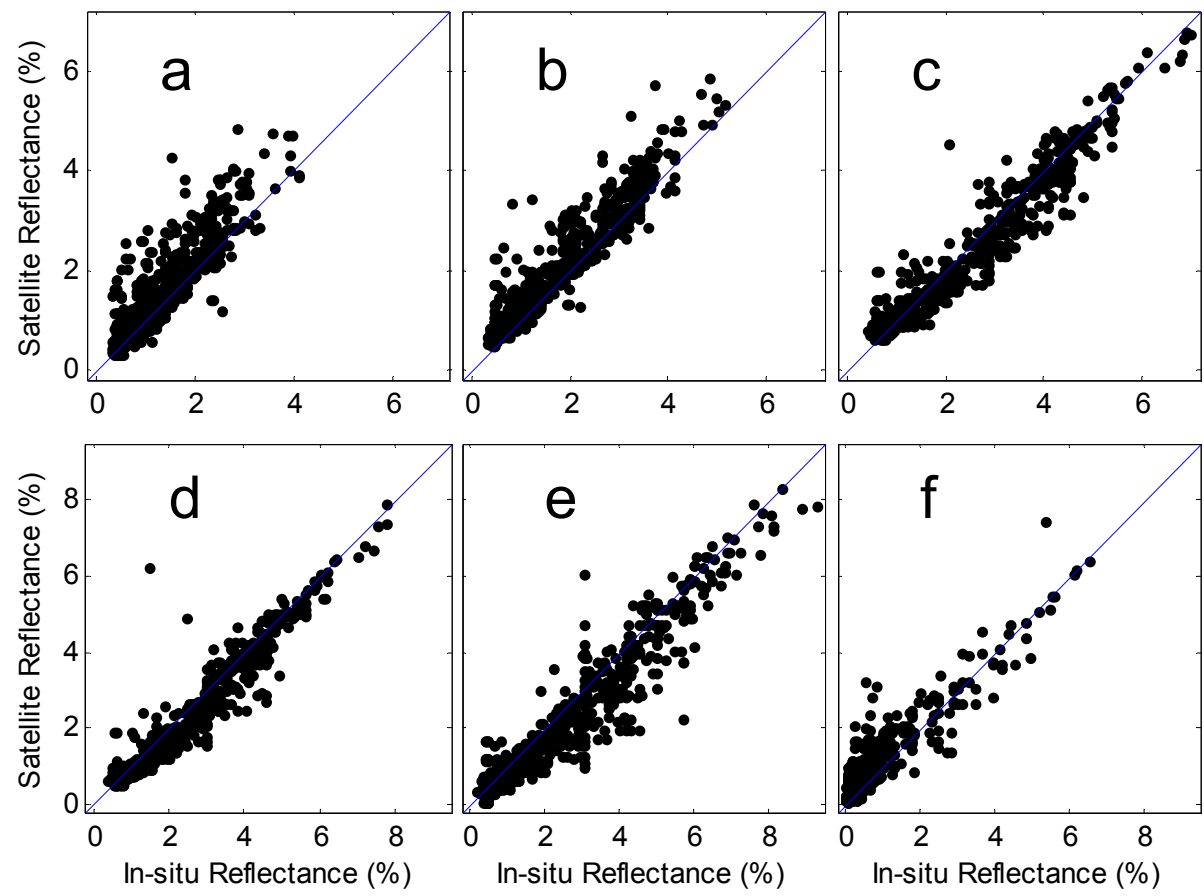

Figure 8. Comparisons of the water-leaving reflectance between the satellite-derived and in situ measurements using the in-water method for Bands 1-6 are shown in (a-f), respectively. 
Because the in situ reflectance in the near-infrared bands over water is unreliable using the in-water method, only six bands are used to evaluate the accuracy. It is clear in Figure 8 that, as with the previous results, most points are tightly clustered around the 1:1 line. However, there are a few pairs that have large differences. There are several factors that can introduce uncertainty in the in situ reflectance when using the in-water method. These uncertainties can be introduced by the in situ measurement during the instrument operations and by the in situ data processing used to deduce the water-leaving reflectance. Frequently, the difference in the reflectance between two measurements from the same station exceeds $10 \%$.

The mean bias and RMSE values of the satellite reflectance in the six bands are listed in Table 3. The bias values vary from $-22.07 \%$ in Band 2 to $+14.97 \%$ in Band 5 with a mean of $13.60 \%$. The RMSE values vary from $17.39 \%-29.72 \%$ with a mean of $22.53 \%$.

Table 3. The performance of the UAC model using in situ reflectance by the in-water method.

\begin{tabular}{cccccccc}
\hline Wavelength $(\mathbf{n m})$ & $\mathbf{4 1 2}$ & $\mathbf{4 4 3}$ & $\mathbf{4 9 0}$ & $\mathbf{5 1 0}$ & $\mathbf{5 5 5}$ & $\mathbf{6 7 0}$ & Mean \\
\hline Bias $(\%)$ & -14.76 & -22.07 & -6.60 & -0.79 & 14.97 & -21.44 & 13.60 \\
RMSE (\%) & 24.60 & 24.91 & 19.68 & 17.39 & 19.94 & 29.72 & 22.53 \\
\hline
\end{tabular}

\section{Discussion}

There are some line-shape points distributed in Figure 6, indicating that one satellite value is corresponding to some different objects of the in situ measurements. Figure 9 shows an example that there are 139 spectra of different objects measured within the area of one pixel in Qingdao (the location is marked in Figure 5). It is clear that the reflectance varies significantly from object to object and over the SeaWiFS wavelength bands, from a low of $0.35 \%-51.16 \%$ in Band 8 . The mean reflectance of these objects is still not suitable to represent the actual mean reflectance of the satellite pixel because it is likely that there are other objects that are still not measured in this area of the same pixel. Therefore, it is difficult to determine which set of objects reflectances is suitable for validating the satellite observation.

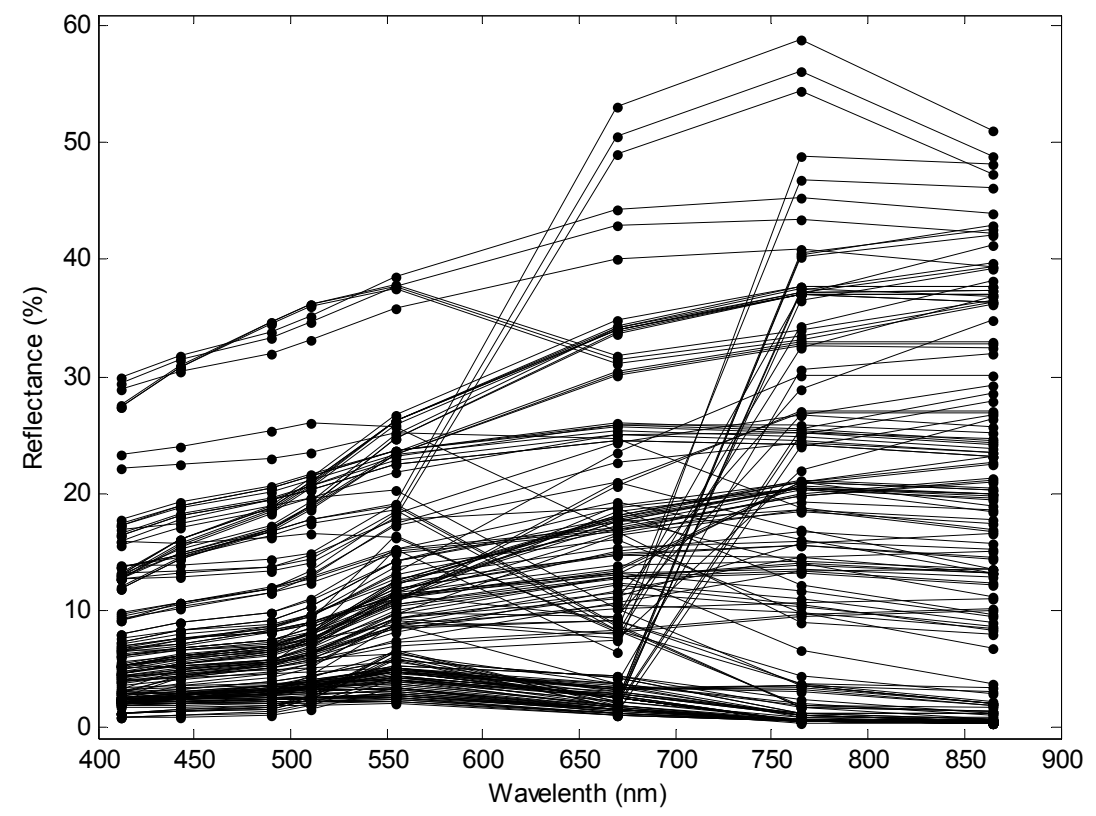

Figure 9. In situ reflectance of 139 different objects within the area of one pixel in Qingdao.

When the mean of the reflectance in Figure 9 is taken as the true value to evaluate the accuracy of these in situ reflectances, the bias and RMSE of the in situ reflectance are listed in the Table 4 . The 
minimum biases in the reflectance in the eight bands range from $-97.98 \%--83.14 \%$ with a mean of $-90.22 \%$, while the maximum biases range from $230.29 \%-344.71 \%$ with a mean of $292.81 \%$. The RMSE values range from $46.71 \%-62.56 \%$ with a mean of $54.62 \%$. When we checked the number of objects measured within the area of one pixel for the all in situ measurements, only one reflectance was measured at most sites. Therefore, there are some differences between the in situ reflectance and the actual mean reflectance of one pixel area. Some differences will degrade obviously the actual accuracy of the satellite-measured reflectance. The actual performance of the UAC model should be better than the evaluated results.

Table 4. The minimum and maximum bias of the in situ reflectance within the area of one pixel, together with the RMSE values when the mean values are taken as the true value.

\begin{tabular}{cccccccccc}
\hline Wavelength (nm) & $\mathbf{4 1 2}$ & $\mathbf{4 4 3}$ & $\mathbf{4 9 0}$ & $\mathbf{5 1 0}$ & $\mathbf{5 5 5}$ & $\mathbf{6 7 0}$ & $\mathbf{7 6 5}$ & $\mathbf{8 6 5}$ & Mean \\
\hline Min_Bias (\%) & -89.21 & -88.96 & -88.44 & -83.79 & -83.14 & -92.46 & -97.77 & -97.98 & -90.22 \\
Max_Bias (\%) & 344.71 & 325.48 & 316.62 & 296.91 & 236.46 & 318.48 & 273.51 & 230.29 & 292.81 \\
RMSE (\%) & 62.56 & 60.45 & 58.77 & 55.55 & 46.71 & 55.21 & 49.38 & 48.33 & 54.62 \\
\hline
\end{tabular}

Normally, the mean of the in situ reflectance is used to evaluate the accuracy of the satellite reflectance values over land areas that possess large spatial variations in reflectance. However, it is often difficult to obtain the actual mean value of the in situ reflectance of the same area covered by one satellite pixel. As the number of objects within the pixel area changes from one to hundreds according to different sites of the dataset, the mean reflectance will actually vary with different numbers of measured objects. Therefore, the mean in situ reflectance is still not suitable to evaluate the accuracy of satellite-derived reflectance over land.

The spatial variation of the reflectance over the ocean is reduced relative to that over land, and therefore, data from several neighboring pixels are normally used in the oceanic validation to increase the number of matched pairs [35]. However, the complexity of the optical properties of coastal waters is well known, and the spatial variation of the water-leaving reflectance in these areas may also be large. Figure 10 shows an image of the mean absolute bias produced from the difference between the reflectance and the mean of a box of $5 \times 5$ pixels. The result demonstrates that the spatial variation of the reflectance is large over both land and ocean with a mean bias of $7.15 \%$. There are $69.34 \%$ of pixels with a bias exceeding $5 \%$ in this image. In fact, the spatial variation at the sub-pixel scale is also large in this region, which can be identified from satellite images with high spatial resolution. Therefore, a box of one pixel is already effectively too large for the validation in coastal regions.

The requirement of the simultaneity of the satellite pass and in situ measurements is also difficult to satisfy if the measurements are taken from a dynamic, rapidly-varying region. For example, the in situ measured reflectance from the Changjiang Estuary and Hangzhou Bay frequently show that the difference of two measurements separated by less than 30 min exceeds $10 \%$. Therefore, a time window of $3 \mathrm{~h}$ is too long for the validation in the coastal regions. Conversely, the reflectance of roads or other land objects is quite stable, so a time window of more than 10 days is still acceptable for the validation in those areas. Unfortunately, the number of matched pairs is very sensitive to the time window adopted for the validation. Only about $15 \%$ of in situ measurements are valid using a $5 \times 5$ box and the 3-h time window rule [35]. Considering the complex spatial variation in this region, the closest matching method with a variable time window is more suitable for establishing the matched pairs for the validation of the UAC model over land and ocean.

To demonstrate the performance of the UAC model, a comparison of the reflectance with the standard product is shown in Figure 11. Both images were processed from the same SeaWiFS data on 24 December 2003. The standard products of SeaWiFS Level-2 data were downloaded from the website (http://oceandata.sci.gsfc.nasa.gov). The product of the website has been reprocessed using the '2014.0' processing version and saved as the netCDF format. The normalized water-leaving reflectance is converted to the reflectance by multiplying by $100 \times \pi$. 


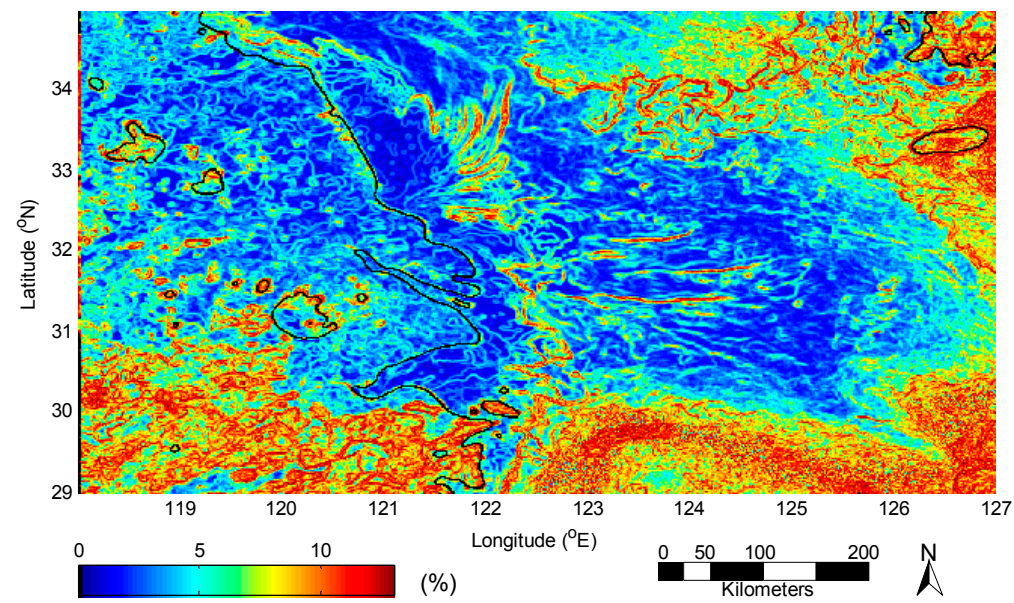

Figure 10. The spatial variation of the ground reflectance as indicated by the relative error of the image pixel where the mean of a $5 \times 5$ pixel box is taken as the truth value. The value of each image pixel comes from the maximum of the values computed from the ground reflectance at eight bands. The coastline is indicated by the black line, and the unit of the color scale is percentage.

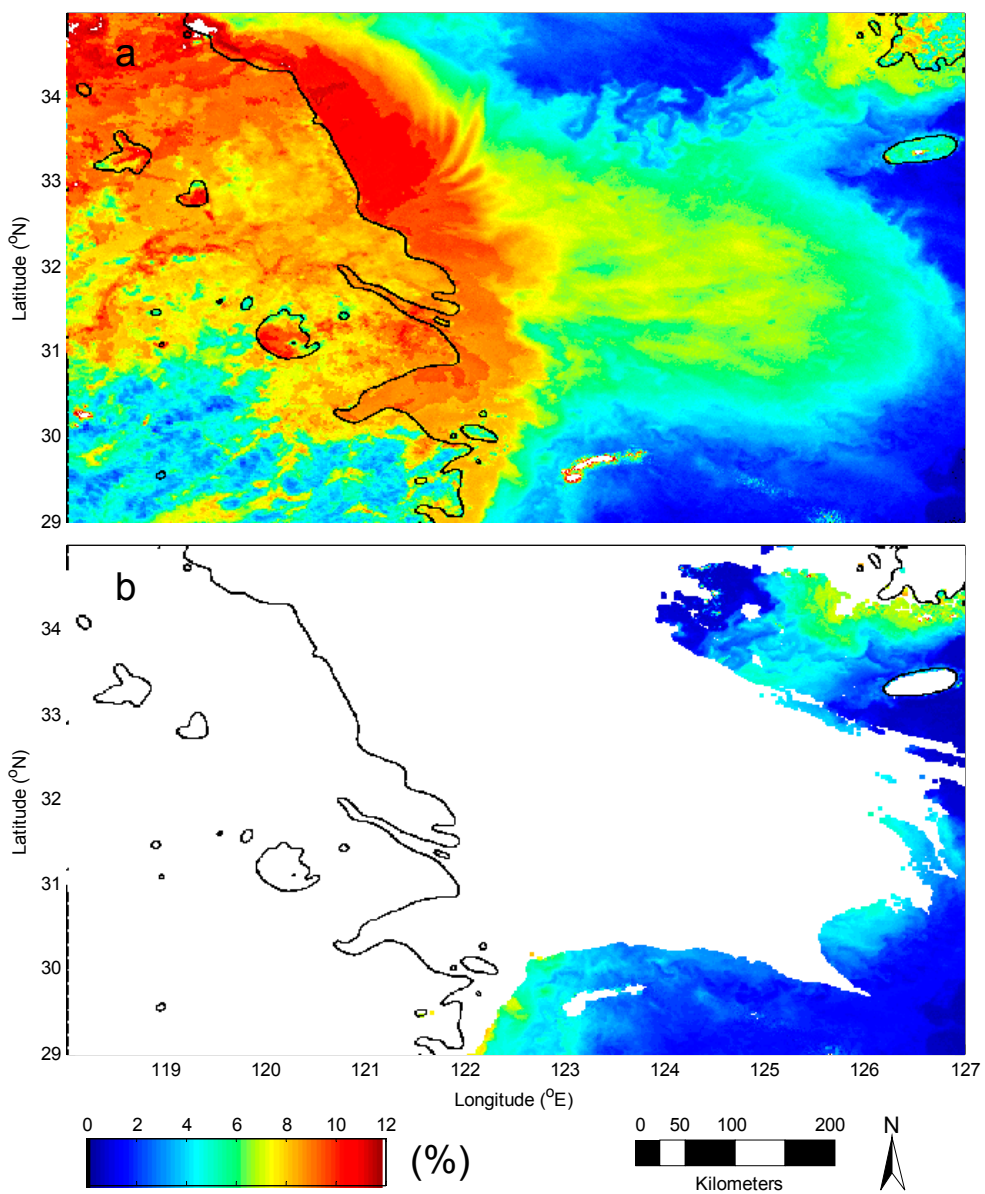

Figure 11. The comparison of the reflectance between (a) the image of Band $5(555 \mathrm{~nm})$ from the UAC model and (b) the image of the normalized water-leaving reflectance at Band 5 obtained from the website (http:/ / oceandata.sci.gsfc.nasa.gov/)with the conversion from the remote sensing reflectance by multiplying by $100 \times \pi$. The values of the images are indicated by the color bar with the reflectance (\%).The white color indicates that the pixel of the image has no valid value. Both have been processed from SeaWiFS data on 24 December 2003. 
The significant difference between the two images in Figure 11 is the number of valid data. There are 538,931 valid pixels for the image of the UAC and 107,867 pixels for the standard product. Especially, there are no valid data in the coastal waters where the water quality is important to be monitored by the satellite ocean color remote sensing. The UAC model provides a powerful tool to measure the water-leaving reflectance in the turbid waters, together with the ground reflectance over the land.

\section{Conclusions}

At present, the approaches used for the atmospheric correction of satellite remote sensing data over oceanic waters were significantly different from those over land. This is mainly caused by obstacles in estimating the aerosol scattering reflectance over land and in turbid waters. The unified algorithm of the atmospheric correction developed herein assumes that the aerosol component can be directly obtained once the ground reflectance has been measured. A rule was designed and implemented to properly select the ground reflectance from a look-up table of in situ measurements. The use of this table provides a unified approach for estimating the aerosol reflectance over both land and ocean. This algorithm provides a tool to process satellite ocean color remote sensing data over land and to do some applications. The one remaining issue with the new algorithm is that interaction effects between the ground and atmospheric reflections need to be included in the model in future improvements.

To evaluate the accuracy of the satellite products was a perplexing task. We believe that the direct comparison of the ground reflectance between satellite estimated and in situ measured may wrongly estimate the accuracy of the satellite products. There are several inevitable factors in establishing the match-ups that may lead to a significant error even in the situation where there is actually no error in the satellite products. The closest matching method, based on the smallest reflectance difference between the satellite-derived and in situ measurements with a variable window time, is a new attempt to establish the matched pairs. Our tests show that it does compensate for some of the deficiencies in estimating the uncertainty of the satellite products. In addition, most in situ reflectance measurements can be used in the evaluation of the satellite products.

The accuracy of the model has been verified by the analysis of a large number of the in situ measurements through the closest matching method. The mean spectral bias of the reflectance over land for matched pairs is $6.59 \%$ with an RMSE of $19.61 \%(N=864)$. The mean bias of the water-leaving reflectance for matched pairs is $7.59 \%$ with an RMSE of $17.10 \%(N=1364)$ for the above-water method and is $13.60 \%$ with an RMSE of $22.53 \%(N=923)$ for the in-water method. Considering the uncertainty introduced in the validation, the performance of the UAC model should be better than the evaluated results.

Acknowledgments: This study is supported by the Public Science and Technology Research Funds Projects of Ocean (201005030) and the National Science Foundation of China (41476156, 41321004). We thank our colleagues from the Second Institute of Oceanography State Oceanic Administration, who took part in the cruises, for their hard work on the in situ measurements. We also want to thank the experts who provided us with their in situ measurements. The three anonymous reviewers provided useful comments and criticism, which helped to improve this paper significantly.

Author Contributions: All authors contributed to the conception of the paper, data processing, analysis and discussion and the writing of the manuscript.

Conflicts of Interest: The authors declare no conflict of interest.

\section{Abbreviations}

The following abbreviations are used in this manuscript:

UAC unified atmospheric correction

LUT look-up table

SeaWiFS the Sea-viewing Wide Field-of-view Sensor

RMSE root mean square error

TOA top of the atmosphere 
BOA black ocean assumption

NIR near-infrared

ASD Analytical Spectral Devices Incorporation

\section{References}

1. Gordon, H.R. Removal of atmospheric effects from the satellite imagery of the oceans. Appl. Opt. 1978, 17, 1631-1636. [CrossRef] [PubMed]

2. Gordon, H.R.; Castano, D.J. Coastal zone color scanner atmospheric correction algorithm: Multiple scattering effects. Appl. Opt. 1987, 26, 2111-2122. [CrossRef] [PubMed]

3. Gordon, H.R.; Brown, J.W.; Evans, R.H. Exact Rayleigh scattering calculations for use with the Nimbus-7 Coastal Zone Color Scanner. Appl. Opt. 1988, 27, 862-871. [CrossRef] [PubMed]

4. Gordon, H.R.; Castano, D.J. Aerosol analysis with the Coastal Zone Color Scanner: A simple method for including multiple scattering effects. Appl. Opt. 1989, 28, 1320-1326. [CrossRef] [PubMed]

5. Gordon, H.R.; Wang, M. Surface-roughness considerations for atmospheric correction of ocean color sensors, II: Error in the retrieval water-leaving radiance. Appl. Opt. 1992, 31, 4261-4267. [CrossRef] [PubMed]

6. Ding, K.; Gordon, H.R. Analysis of the influence of A-band absorption on atmospheric correction of ocean color imagery. Appl. Opt. 1995, 34, 2068-2080. [CrossRef] [PubMed]

7. Wang, M. Validation study of the SeaWiFS oxygen A-band absorption correction: Comparing the retrieved cloud optical thicknesses from SeaWiFS measurements. Appl. Opt. 1999, 38, 937-944. [CrossRef] [PubMed]

8. Wang, M. Aerosol polarization effects on atmospheric correction and aerosol retrievals in ocean color remote sensing. Appl. Opt. 2006, 45, 8951-8963. [CrossRef] [PubMed]

9. Siegel, D.A.; Wang, M.; Maritorena, S.; Robinson, W. Atmospheric correction of satellite ocean color imagery: The black pixel assumption. Appl. Opt. 2000, 39, 3582-3591. [CrossRef] [PubMed]

10. Wang, M.; Shi, W. Estimation of ocean contribution at the MODIS near-infrared wavelengths along the east coast of the U.S.: Two case studies. Geophy. Res. Lett. 2005, 32. [CrossRef]

11. Hu, C.; Carder, K.L.; Muller-Karger, F.E. Atmospheric correction of SeaWiFS imagery over turbid coastal waters: A practical method. Remote Sens. Environ. 2000, 74, 195-206. [CrossRef]

12. Ruddick, K.G.; Ovidio, F.; Rijkeboer, M. Atmospheric correction of SeaWiFS imagery for turbid coastal and inland waters. Appl. Opt. 2000, 39, 897-912. [CrossRef] [PubMed]

13. Wang, M. Remote sensing of the ocean contributions from ultraviolet to near-infrared using the shortwave infrared bands: Simulations. Appl. Opt. 2007, 46, 1535-1547. [CrossRef] [PubMed]

14. Shanmugan, P.; Ahn, Y. New atmospheric correction technique to retrieve the ocean colour from SeaWiFS imagery in complex coastal waters. J. Opt. A Pure Appl. Opt. 2007, 9, 511-530. [CrossRef]

15. Ahn, J.; Park, Y.; Ryu, J.; Lee, B.; Oh, I. Development of atmospheric correction algorithm for geostationary ocean color imager (GOCI). Ocean Sci. J. 2012, 47, 247-259. [CrossRef]

16. He, X.; Bai, Y.; Pan, D.; Huang, N.; Dong, X.; Chen, J.; Chen, C.T.A.; Cui, Q. Using geostationary satellite ocean color data to map the diurnal dynamics of suspended particulate matter in coastal waters. Remote Sens. Environ. 2013, 133, 225-239. [CrossRef]

17. Gordon, H.R.; Du, T.; Zhang, T. Remote sensing ocean color and aerosol properties: Resolving the issue of aerosol absorption. Appl. Opt. 1997, 36, 8670-8684. [CrossRef] [PubMed]

18. Chomko, R.M.; Gordon, H.R. Atmospheric correction of ocean color imagery: Test of the spectral optimization algorithm with SeaWiFS. Appl. Opt. 2001, 40, 2973-2984. [CrossRef] [PubMed]

19. Chomko, R.M.; Gordon, H.R.; Maritorena, S.; Siegel, D.A. Simultaneous retrieval of oceanic and atmospheric parameters for ocean color imagery by spectral optimization: A validation. Remote Sens. Environ. 2003, 84, 208-220. [CrossRef]

20. Moulin, C.; Gordon, H.R.; Banzon, V.F.; Evans, R.H. Assessment of Saharan dust absorption in the visible from SeaWiFS imagery. J. Geophys. Res. 2001, 106, 18239-18249. [CrossRef]

21. Schroeder, T.; Behnert, I.; Schaale, M.; Fischer, J.; Doerffer, R. Atmospheric correction algorithm for MERIS above case-2 waters. Int. J. Remote Sens. 2007, 28, 1469-1486. [CrossRef]

22. Brajard, J.; Santer, R.; Crépon, M.; Thiria, S. Atmospheric correction of MERIS data for case-2 waters using a neuro-variational inversion. Remote Sens. Environ. 2012, 126, 51-61. [CrossRef]

23. Kaufman, Y.J.; Sendra, C. Algorithm for automatic atmospheric corrections to visible and near-IR satellite imagery. Int. J. Remote Sens. 1988, 9, 1357-1381. [CrossRef] 
24. Hagolle, O.; Huc, M.; Pascual, D.V.; Dedieu, G. A multi-temporal and multi-spectral method to estimate aerosol optical thickness over land, for the atmospheric correction of FormoSat-2, LandSat, VEN $\mu \mathrm{S}$ and sentinel-2 images. Remote Sens. 2015, 7, 2668-2691. [CrossRef]

25. Hall, F.G.; Strebel, D.E.; Nickeson, J.E.; Goetz, S.J. Radiometric rectification: Toward a common radiometric response among multidate, multisensor images. Remote Sens. Environ. 1991, 35, 11-27. [CrossRef]

26. Richter, R. A spatially adaptive fast atmospheric correction algorithm. Int. J. Remote Sens. 1996, 17, $1201-1214$. [CrossRef]

27. Tanre, D.; Legrand, M. On the satellite retrieval of Saharan dust optical thickness over land: Two different approaches. J. Geophys. Res. 1991, 96, 5221-5227. [CrossRef]

28. Gao, B.C.; Montes, M.J.; Davis, C.O.; Goetz, A.F.H. Atmospheric correction algorithms for hyperspectral remote sensing data of land and ocean. Remote Sens. Environ. 2009, 113, S17-S24. [CrossRef]

29. Miura, T.; Huete, A.R.; Yoshioka, H.; Holben, B.N. An error and sensitivity analysis of atmospheric resistant vegetation indices derived from dark target-based atmospheric correction. Remote Sens. Environ. 2001, 78, 284-298. [CrossRef]

30. Vermote, E.F.; El Saleous, N.Z.; Justice, C.O. Atmospheric correction of MODIS data in the visible to middle infrared: First results. Remote Sens. Environ. 2002, 83, 97-111. [CrossRef]

31. Hadjimitsis, D.G.; Papadavid, G.; Agapiou1, A.; Themistocleous, K.; Hadjimitsis, M.G.; Retalis, A. Atmospheric correction for satellite remotely sensed data intended for agricultural applications: Impact on vegetation indices. Nat. Hazards Earth Syst. Sci. 2010, 10, 89-95. [CrossRef]

32. Mao, Z.; Chen, J.; Pan, D.; Tao, B.; Zhu, Q. A new approach to estimate the aerosol scattering ratios for the atmospheric correction of satellite remote sensing data in coastal regions. Remote Sens. Environ. 2013, 132, 186-194. [CrossRef]

33. Mao, Z.; Pan, D.; Hao, Z.; Chen, J.; Tao, B.; Zhu, Q. A potentially universal algorithm for estimating aerosol scattering reflectance from satellite remote sensing data. Remote Sens. Environ. 2014, 142, 131-140. [CrossRef]

34. Fernandes, M.J.; Lázaro, C.; Nunes, A.L.; Scharroo, R. Atmospheric corrections for altimetry studies over inland water. Remote Sens. 2014, 6, 4952-4997. [CrossRef]

35. Bailey, S.W.; Werdell, P.J. A multi-sensor approach for the on-orbit validation of ocean color satellite data products. Remote Sens. Environ. 2006, 102, 12-23. [CrossRef]

(C) 2016 by the authors; licensee MDPI, Basel, Switzerland. This article is an open access article distributed under the terms and conditions of the Creative Commons Attribution (CC-BY) license (http://creativecommons.org/licenses/by/4.0/). 